\title{
Probiotics and Gut Health in Athletes
}

\section{Authors: Mary P. Miles}

This is a post-peer-review, pre-copyedit version of an article published in Current Nutrition Reports. The final authenticated version is available online at: https://doi.org/10.1007/ s13668-020-00316-2. The following terms of use apply: https://www.springer.com/gp/openaccess/publication-policies/aam-terms-of-use.

Miles, Mary P. "Probiotics and Gut Health in Athletes." Current Nutrition Reports 9, no. 3 (July 21, 2020): 129-136. doi:10.1007/s13668-020-00316-2.

Made available through Montana State University's ScholarWorks 
Title: $\quad$ Probiotics and Gut Health in Athletes

Author: $\quad$ Mary P. Miles, PhD, FACSM

Montana State University-Bozeman

Department of Health and Human Development

Box 3540, Herrick Hall

Bozeman, MT 59717 USA

mmiles@montana.edu

Key words: probiotics; athletes; gut microbiota; gastrointestinal symptoms; endotoxemia; gut barrier function

\begin{abstract}
Purpose of review: To provide a focused analysis of the challenges to gut health in athletes and examine recent research aimed at determining the impact of probiotics on preventing gastrointestinal (GI) symptoms and loss of barrier function in athletes. Recent findings: Frequency and severity of GI symptoms during training or competition were reduced by approximately one third in studies demonstrating efficacy. Improvement of GI symptoms with probiotic supplementation was measured in both single strain Lactobacillus and multi-strain Lactobacillus and Bifidobacterim probiotics, while improvement in gut barrier function was only measured for multi-strain probiotics. Likelihood of efficacy increased with duration of supplementation. Summary: The greatest efficacy for reducing GI symptom frequency and severity, as well as improving or preserving gut barrier function during exercise training and competition appears to be for multi-strain Lactobacillus and Bifidobacterium probiotic cocktails supplemented for at least 11 weeks.
\end{abstract}




\section{Introduction}

The physiologic and nutritional demands of exercise training and competition may be beneficially impacted by probiotic supplementation to support gut health. A healthy gut is both free from pathology and robustly functional. A unique challenge facing athletes is that the gut is designed to function optimally at rest when blood flow is increased and function is stimulated by parasympathetic activation, while athletes need the gut to function optimally during exercise when blood flow is reduced and functional capacity is limited by sympathetic activation [1, 2]. The gastrointestinal (GI) tract competes for blood flow with the cardiorespiratory, musculoskeletal, integumentary, and other systems of the body during exercise [3,4]. Fortunately for survival but unfortunately for the gut during exercise, the $\mathrm{Gl}$ tract is at a disadvantage in this competition for resources. As a result, aspects of gut function that are challenged during exercise are 1) digestion and absorption, 2) unidirectional transit of gastrointestinal contents, 3) barrier function to prevent entry of gut microbial toxins, and 4) protection against ingested pathogens $[2,5]$. Coupling the demands and stresses of exercise with ingestion of foods that require extra effort and resources to process increases the likelihood of surpassing functional limits of the gut to induce gastrointestinal problems $[1,3,5]$. As a result, athletes may benefit from supplements, such as probiotics, that promote gut health and resilience to exercise-induced symptoms and impairments.

In 2018, the International Olympic Committee (IOC) identified probiotics as a supplement moderately effective in supporting immune health to reduce the impact of respiratory tract infections and a need for further research to clarify impact on gut related issues and infections [6, 7]. A recent position stand of the International Society of Sports Nutrition (ISSN) provides an excellent summary of the mechanisms and available research regarding the use of probiotic supplements in athletes for promotion of health, improvement in sports performance, and recovery from exercise [5]. The purpose of this review is to provide a focused analysis of the challenges to gut health in athletes and examine recent research aimed at determining the 
impact of probiotics on preventing gastrointestinal symptoms and loss of barrier function in athletes.

\section{Search Strategy and Selection Criteria}

For the review of current research studies relating to probiotics and gut health in athletes, PubMed was searched using the terms [athlete or "exercise training" or sport] and probiotic with filtering to select clinical trials and meta-analyses. Screening of titles and abstracts was used to narrow the search to original research articles that included measurements relating to gut health including barrier function, gastrointestinal disturbances, and mucosal immunity. Search results were validated by cross checking with recent systematic reviews [5, 8-10]. Additional research articles related to gut health, probiotics, and the gut microbiome were used to describe and explain background and mechanisms.

\section{Probiotics and Research Limitations}

Probiotics are broadly defined as "live microorganisms that, when administered in adequate amounts, confer a health benefit on the host" [11]. Gut function for digestion and absorption of nutrients, preventing bacterial toxins from entering the body, and immune function are heavily influenced by the gut microbiota, a diverse community of microorganisms residing in the GI tract [12]. The aim of probiotic supplementation is to increase the relative abundance of bacteria in the gut that favorably impact gut health and function. For a microbe to be classified as a probiotic, it must be safe, functional, and usable [13]. The key elements of safety are a history of safe use and no risk of promoting resistance to antibiotics with regulatory status equivalent to "generally regarded as safe". To be functional, a microbial strain must be able to withstand the acidic environment (low $\mathrm{pH})$ and antimicrobial defenses within the gut, compete with the existing gut microbiota to survive, adhere and colonize within the gut, and provide benefits such as antagonism toward pathogenic microbes. Additionally, for the practical purposes of producing and distributing probiotic supplements, a microbe that meets the criteria to be a probiotic must also have the capacity to be mass produced and then stable in its 
supplemental form, e.g. in a capsule. There are a number of different bacterial genera used as probiotics, including Lactobacillus, Bifidobacterium, Lactococcus, and Enterococcus [13].

While safety and usability of probiotics are straightforward concepts, a more complex consideration regarding efficacy of probiotics is that individual differences in the gut microbiota impact colonization (lasting presence) and effectiveness of probiotics. The environment in GI tract influences survival and microbial colonization and is largely impacted by the cumulative influence of the resident microbes. For example, individual microbial species compete for available resources (fuel) create a hostile environment for their competitors in a way that can make it difficult for newly introduced species to survive. As a result, the vast inter-individual variability in composition and relative abundance of species within the gut microbiota contributes to variability in the quantity of probiotic microbes that subsequently are available to manifest changes in gut health. Recovery of a probiotics in fecal samples is an indication that the probiotic has colonized and differs by probiotic strain [14]. Two studies by West et al. provide examples to illustrate the impact of inter-individual variability in response to probiotic supplementation $[15,16]$. In one study the researchers measured a range of 2 - to 43 -fold for the increase in one of the strains, Lactobacillus paracasei, and no change in the remaining three species in the cocktail (Bifidobacterium animalis, Lactobacillus acidophilus, and Lactobacillus rhamnosus) after 21 days of supplementation in physically active, health males . Further, interindividual variability was high (standard deviations often greater than the mean) and means of several genera changed by several orders of magnitude between pre- and post-testing in both probiotic and placebo groups. In a second study of endurance cyclists, the researchers measured a range of 3- to 21 -fold increase in men and a 0.7 - to 47 -fold increase in women after 11 weeks of supplementation with Lactobacillus fermentum. Thus, there is substantial interindividual variability in the colonization of supplemented probiotics, which may be paralleled by the magnitude of impact on gut health. Unless studies report changes in the probiotic, which 
most studies do not, it is difficult to know whether probiotic supplements that fail to demonstrate efficacy have failed because the probiotic did not colonize sufficiently or because the probiotic colonized but did not have a measurable benefit.

Gastrointestinal symptoms of nausea, vomiting, cramping or discomfort, and diarrhea in athletes may be caused by infections, adverse reactions to ingested food, or stresses to the gut during exercise. The mechanisms through which probiotics could prevent these symptoms differs by cause. Without specific testing to identify pathogens or specific food intolerances and dietary controls, it is not possible to definitively link a specific cause to symptoms athletes experience before, during or after exercising. While it is difficult to link symptoms to cause, probiotics have the potential to improve immune function and resistance to infections, particularly respiratory tract infections $[5,6,7]$. However, gastrointestinal infection episodes are relatively rare in athletic populations and may be caused by viruses, bacteria, parasites, and other pathogens $[5,17]$. Thus, it is likely that symptoms commonly experienced during and soon after exercise are linked to the stresses of exercise rather than infection. In addition to gut barrier function impaired in large part by exercise-induced splanchnic hypoperfusion [4], this review of probiotic efficacy is focused on symptoms, regardless of underlying cause.

In summary, it is important to be aware of the challenges and limitations of research assessing the efficacy of probiotics on gut health in athletes. With that in mind, a review of available research in the following sections does find that some probiotics may favorably impact GI symptoms and gut barrier function given a sufficiently long duration of supplementation. The impact of probiotics on gut health in athletes is an emerging area of research with current gaps that include focused research on individuals prone to $\mathrm{Gl}$ issues during exercise, specific $\mathrm{GI}$ symptoms, dietary controls, inter-individual variability in colonization of probiotics, the impact cosupplementation with pre-biotics to support colonization of probiotics.

Impact of Probiotics on Gastrointestinal Symptoms During Training 
There is only modest evidence to suggest that single strain Lactobacillus probiotics protect athletes from GI symptoms when comparing episodes, duration, and severity of GI symptoms during several weeks intensive training (Table 1). For example, in a randomized, placebo-controlled, parallel trial in which 119 individuals training for a marathon kept symptom logs for three months before and one month after the race, Kekkonen et al. measured GI symptoms in $27 \%$ and $32 \%$ of runners with the average duration of symptoms of 2.9 versus 4.3 days ( $p=0.35$ ) for the probiotic (Lactobacillus rhamnosus $G G$ ) compared to placebo group during 3 months of marathon training [18]. However, the probiotic group reported $57 \%$ fewer days of Gl symptoms during the two weeks following completion of the marathon, indicating a potential benefit. In a similar research design, Gleeson et al. monitored GI symptoms for 65 recreationally active individuals during a 16 -week period of supplementation and measured $2 \%$ versus $3 \%$ of days for the probiotic (Lactobacillus casei Shirota) compared to placebo. In contrast, West et al. monitored 88 male cyclists and triathletes supplemented with probiotic (Lactobacillus fermentum PCC) or placebo using daily symptom logs during 11 weeks of training and measured twice as many GI symptom episodes with longer duration, but potentially lower symptom severity in the probiotic compared to placebo group [15]. No differences were measured in female cyclists and triathletes in this same study. These studies do not specifically report the temporal relationship of the symptoms to training bouts to speculate as to whether symptoms are infectious episodes or exercise-induced symptoms, but the overall narrative is for little if any impact of probiotics on GI symptoms.

In contrast to these single strain Lactobacillus probiotics, evidence to support potential reductions in $\mathrm{Gl}$ infections during training is a bit stronger for multi-strain probiotics (Table 1). While multiple studies of Lactobacillus and Bifidobacterium multi-strain probiotic regimens have reported no or little impact on number, duration, or severity of GI symptom episodes [19-21], there are two studies measuring benefits from these multi-strain regimens. Roberts et al. compared a multi-strain probiotic cocktail with and without added antioxidants and found about 
one third lower symptom counts and ratings of symptom severity during triathlon training [22]. Pugh et al. also measured lower GI symptoms with a similar probiotic supplement in recreational runners preparing for a marathon [23]. The cocktail regimens that were not effective at reducing GI symptoms overlap in some strains and differ in others compared to the cocktails that were effective, so it is difficult to sort out the most beneficial strains. However, the two effective cocktails both shared Lactobacillus acidophilus CUL-60 and CUL21, Bifidobacterium bifidum, and Bifidobacterium animalis lactis CUL34, suggesting that these four probiotic strains are candidate strains that may be the most beneficial for attenuating GI symptoms with exercise training.

\section{Impact of Probiotics on Gastrointestinal Symptoms During Competition}

Many athletes experience GI symptoms and resulting performance impairment during competition, particularly for endurance events such as marathons and triathlons. Symptoms experienced during endurance competition are likely caused by a combination stresses including splanchnic hypoperfusion (reduced blood flow to the gut), mechanical jarring (bouncing up and down), dehydration, and ingestion of food and drink, particularly high osmolality (concentration of solutes such as sugars and electrolytes, e.g. consuming concentrated gels) drinks [1, 3, 24]. With variation in severity and impact on performance from mild discomfort to termination of competition, the range of athletes reporting GI symptoms during endurance events is from 5 to $95 \%$ with a general consensus that $30-50 \%$ is somewhat typical [3]. Some athletes are more prone to GI problems during competition; however, no studies have focused on the use of probiotics in prone individuals or included historical competition symptomology in the analysis of probiotic efficacy. Relatively little research has been performed on the efficacy of probiotics to prevent or attenuate GI symptoms during competition or a single event.

With few studies investigating the impact of probiotics on Gl symptoms during endurance competition, the evidence of probiotic efficacy is mixed (Table 1). The same 
Lactobacillus and Bifidobacterium multi-strain cocktail that lowered GI symptoms during training also attenuated symptoms during the final third of a marathon [23]. With four weeks of probiotic supplementation prior to a triathlon, global GI severity scores during the final third of the race were reduced by approximately one third for the probiotic compared to placebo group, without specific information regarding which symptoms runners experienced. Using a different Lactobacillus and Bifidobacterium multi-strain cocktail, Shing et al. found no difference between probiotic and placebo in a cross-over study comparing Gl symptoms during a run to fatigue in the heat. Run time was increased in the probiotic compared to placebo trial condition and ratings of $\mathrm{Gl}$ symptoms averaged just above 1 on a 4-point scale in which 1 corresponded to "no/hardly any complaint". Thus, it would not have been possible for probiotic to be lower than placebo for this trial in which participants appeared to tolerate the exercise well regardless of treatment. These studies do not provide sufficient evidence to draw conclusions about the efficacy of probiotics to reduce GI symptoms during competition, but they do provide a rationale for further investigation focused on athletes prone to Gl symptoms during competition.

\section{Impact of Probiotics on Gut Barrier Function}

Manipulation of the gut microbiota with probiotic supplementation to improve barrier function could be beneficial to athletes in many ways. The composition and function of the gut microbiota impacts integrity of the mucosal barrier preventing translocation of toxins and other compounds from the gut into the systemic circulation [25]. Several studies have demonstrated that exercise increases permeability of the gut to allow translocation of toxins from the gut into the systemic circulation [26]. Increased gut permeability has been measured with relatively low exercise stresses such as 20 minutes of running at $80 \%$ of $\mathrm{VO}_{2}$ max or 60 minutes of cycling at $70 \%$ of $\mathrm{VO}_{2} \mathrm{max}$, but it is generally accepted that prolonged exercise ( $\geq 2 \mathrm{~h}$ ) has the greatest impact on gut permeability $[2,4,26]$. Exercise-induced gut permeability is exacerbated by dehydration, heat stress, and ingestion of non-steroidal anti-inflammatory drugs [25, 27]. The main consequence of increased permeability is increased levels of bacterial endotoxin, a potent 
pro-inflammatory stimulus, in the systemic circulation after marathon running, exercise in the heat to a body core temperature of $39.5^{\circ} \mathrm{C}$ and above, long-distance triathlon [28-30]. Increased endotoxin coincides with increases in inflammatory cytokines and acute phase proteins [29-31]. Further, Brock-Utne et al. reported that marathon runners with the highest post-race endotoxin levels were four times more likely to experience nausea, vomiting, and or diarrhea compared to runners with lowest endotoxin levels [32], however, this association is not consistent across all studies [33]. Thus, improved barrier function enhances resilience against exercise-induced endotoxemia and inflammation, and possibly against gastrointestinal disturbances and heat stress.

Several research studies have been undertaken to determine the efficacy of probiotics to improve gut barrier function in athletes (Table 1). While the overall picture of probiotic impact on gut barrier function appears mixed, closer analysis suggests that single strain probiotics are not effective, multi-strain cocktails for six weeks or shorter are not effective, and there are multistrain cocktails overlapping in composition that when supplemented for 12-14 weeks may lower gut permeability during training and prevent increased permeability during prolonged endurance competition. It should be noted that there is substantial inter-individual variability and research focusing on those athletes most susceptible to exercise-induced loss of gut barrier function is most likely to be demonstrate probiotic efficacy. Lamprecht et al. measured elevated zonulin, a marker of compromised gut barrier function, in all athletes prior to treatment and a $20 \%$ reduction in those treated with a multi-strain probiotic for 14 weeks [34]. The probiotic cocktail consisted of Lactobacillus acidophilus W22, Lactoabcillus brevis W63, Lactococcus lactis W58, Bifidobacterium bifidum W23, Bifidobacterium lactis W51, and Enterococcus Faucium W54, in which Lactobacillus acidophilus and Bifidobacterium bifidum overlap with the probiotics that reduced GI symptoms during training and a marathon $[22,23]$ and prevented an exerciseinduced increase in permeability during a triathlon [22]. While more research to confirm potential benefits of probiotics on gut health are needed, available research suggests that 12-14 weeks of 
supplementation with a multi-strain probiotic containing Lactobacillus acidophilus and

Bifidobacterium bifidum may be effective while shorter durations of supplementation and or alternative probiotic strain cocktails are not effective.

\section{Probiotic Strains and Duration of Supplementation Effective for Gut Health Benefits in}

\section{Athletes}

Studies demonstrating efficacy for gut health were either single strain Lactobacillus or multi-strain Lactobacillus and Bifidobacterium probiotics. One common characteristic of these strains is that they are lactic acid producers, and lactic acid bacteria are known to improve resistance to food borne bacterial infections, lactose tolerance, innate and acquired immunity, and other benefits [35]. Lactobacillus and Bifidobacterium genera contain many species that are used as probiotics with general functions of producing antimicrobial peptides, digesting some fibers, competitive exclusion of pathogenic bacteria in the gut, enhancement of mucosal immunity [36]. Further, as probiotics, all are considered to be well-tolerated, beneficial to health, and beneficial to the composition of the gut microbiome, with few if any negative side effects [35]. The probiotic strains investigated that were found to confer benefit in more than one study include Lactobacillus acidophilus, Bifidobacterium bifidum, and Bifidobacterium animalis lactis $[22,23,34]$. The specific attributes of these probiotic (sub)strains that may have made them particularly beneficial over other Lactobacillus and Bifidobacterium (sub)strains are not readily apparent, however, there are a number of GI health benefits attributed to each that may be relevant to the benefits measured:

Lactobacillus acidophilus. This strain of bacteria is capable of creating antimicrobial compounds and lowering $\mathrm{pH}$, which may contribute to its potential to enhance abundance of symbiotic bacteria within the gut microbiome. Some strains of Lactobacillus acidophilus have been shown in vitro to be foodborne disease agents, e.g. Staphylococcus aureus, and Salmonella typhimurium [37]. Among the established benefits of this probiotic are improved 
lactose tolerance, attenuation of small intestine bacterial overgrowth, decreased colonic tumorigenesis, enhancement of mucosal immunity, and anti-inflammatory effects [35, 38, 39].

Bifidobacterium bifidum. This strain of bacteria is one of the most abundant in breast milk and has many established benefits for neonatal health [36]. Some strains of Bifidobacterium bifidis have been demonstrated to suppress irritable bowel syndrome and allergic responses [36].

Bifidobacterium animalis lactis. Relatively few studies have focused on this particular subspecies of Bifidobacterium animalis, but in addition to the two clinical trials described herein on athletes, other studies have identified no effect on eczema [40], lowering of respiratory tract infections [41], and established that it is safe for women to use during pregnancy [42]. Effective probiotics strains may have additional benefits that have not been identified, or they may be particularly adept at surviving through the digestive process, adhering to the colonic mucosa, and colonizing in the gut, all of which are characteristics required of successful probiotics.

While there were a variety of probiotic strains that produced some benefit, the overwhelming similarity across studies that demonstrated GI benefit in athletes was duration of supplementation (Table 1). Four out of five studies reporting attenuation of $\mathrm{Gl}$ symptoms or protection of gut barrier function had supplement durations of at least 11 weeks. One of five studies reporting benefit supplemented with a multi-strain cocktail for four weeks. One study with multi-strain supplementation for 27 weeks showed no benefit in rugby players, but GI symptoms were not a problem in this population and improvement with a probiotic was not likely [20]. This was the only multi-strain probiotic study with supplementation greater than 11 weeks that did not show some gut health benefit. The majority of studies reporting no GI benefit had supplement durations of one to eight weeks, with one single-strain supplement study reporting no gut related benefit even with supplementation of 12 weeks. 


\section{Conclusions}

Gastrointestinal symptoms and impairment of gut barrier function during exercise training and competition may be favorably impacted by probiotics to support gut health in some athletes. A variety of Lactobacillus and Bifidobacterium probiotic strains showed a degree of efficacy to reduce frequency and severity of GI symptoms, but greatest efficacy appears to be for multi-strain probiotic cocktails supplemented for at least 11 weeks. Efficacy of probiotics to improve or maintain gut barrier function in athletes has only been demonstrated for multi-strain cocktails supplemented for a minimum of 12 weeks. Additional research is needed to determine the impact of probiotics in athletes prone to GI symptoms and or exercise-induced endotoxemia, inter-individual variability in colonization of probiotics, and potential strategies to co-supplement prebiotics that may enhance probiotic efficacy. 


\section{References}

*Indicates paper of particular importance.

1. Brouns F, Beckers E. Is the gut an athletic organ? Digestion, absorption and exercise. Sports Med. 1993;15(4):242-57. doi:10.2165/00007256-199315040-00003.

*2. Costa RJS, Snipe RMJ, Kitic CM, Gibson PR. Systematic review: exercise-induced gastrointestinal syndrome-implications for health and intestinal disease. Alimentary pharmacology \& therapeutics. 2017;46(3):246-65. doi:10.1111/apt.14157.

This systematic review provides extensive data to describe the etiology and implications of exercise-induced gastrointestinal symptoms.

3. de Oliveira EP, Burini RC, Jeukendrup A. Gastrointestinal complaints during exercise: prevalence, etiology, and nutritional recommendations. Sports medicine (Auckland, NZ). 2014;44 Suppl 1(Suppl 1):S79-S85. doi:10.1007/s40279-014-0153-2.

4. van Wijck K, Lenaerts K, van Loon LJ, Peters WH, Buurman WA, Dejong CH. Exerciseinduced splanchnic hypoperfusion results in gut dysfunction in healthy men. PLoS One. 2011;6(7):e22366. doi:10.1371/journal.pone.0022366.

*5. Jager R, Mohr AE, Carpenter KC, Kerksick CM, Purpura M, Moussa A et al. International Society of Sports Nutrition Position Stand: Probiotics. J Int Soc Sports Nutr. 2019;16(1):62. doi:10.1186/s12970-019-0329-0.

This position stand provides a comprehensive review and evidence-based recommendations regarding the use of probiotics in athletes for a broad spectrum of applications including incidence and severity of respiratory tract infections, performance enhancement, and recovery from exercise.

6. Maughan RJ, Burke LM, Dvorak J, Larson-Meyer DE, Peeling P, Phillips SM et al. IOC Consensus Statement: Dietary Supplements and the High-Performance Athlete. International journal of sport nutrition and exercise metabolism. 2018;28(2):104-25. doi:10.1123/ijsnem.20180020. 
7. Rawson ES, Miles MP, Larson-Meyer DE. Dietary Supplements for Health, Adaptation, and Recovery in Athletes. International journal of sport nutrition and exercise metabolism. 2018;28(2):188-99. doi:10.1123/ijsnem.2017-0340.

8. Möller GB, da Cunha Goulart MJV, Nicoletto BB, Alves FD, Schneider CD. Supplementation of Probiotics and Its Effects on Physically Active Individuals and Athletes: Systematic Review. International journal of sport nutrition and exercise metabolism. 2019;29(5):481-92. doi:10.1123/ijsnem.2018-0227.

9. Wosinska L, Cotter PD, O'Sullivan O, Guinane C. The Potential Impact of Probiotics on the Gut Microbiome of Athletes. Nutrients. 2019;11(10):2270. doi:10.3390/nu11102270.

10. Moller GB, Goulart M, Nicoletto BB, Alves FD, Schneider CD. Supplementation of Probiotics and Its Effects on Physically Active Individuals and Athletes: Systematic Review. International journal of sport nutrition and exercise metabolism. 2019;29(5):481-92. doi:10.1123/ijsnem.20180227.

11. Hill C, Guarner F, Reid G, Gibson GR, Merenstein DJ, Pot B et al. Expert consensus document. The International Scientific Association for Probiotics and Prebiotics consensus statement on the scope and appropriate use of the term probiotic. Nat Rev Gastroenterol Hepatol. 2014;11(8):506-14. doi:10.1038/nrgastro.2014.66.

12. Miles MP, Wilson S, Yeoman CJ. Physical Activity and Inflammation Phenotype Conversion. Journal of Clinical Exercise Physiology. 2019;8(2):64-73.

13. Markowiak P, Slizewska K. Effects of Probiotics, Prebiotics, and Synbiotics on Human Health. Nutrients. 2017;9(9). doi:10.3390/nu9091021.

14. Larsen CN, Nielsen S, Kaestel P, Brockmann E, Bennedsen M, Christensen HR et al. Doseresponse study of probiotic bacteria Bifidobacterium animalis subsp lactis BB-12 and Lactobacillus paracasei subsp paracasei CRL-341 in healthy young adults. European journal of clinical nutrition. 2006;60(11):1284-93. doi:10.1038/sj.ejcn.1602450. 
15. West NP, Pyne DB, Cripps AW, Hopkins WG, Eskesen DC, Jairath A et al. Lactobacillus fermentum $(\mathrm{PCC} \otimes)$ supplementation and gastrointestinal and respiratory-tract illness symptoms: a randomised control trial in athletes. Nutrition journal. 2011;10:30-. doi:10.1186/1475-2891-1030.

16. West NP, Pyne DB, Cripps AW, Christophersen CT, Conlon MA, Fricker PA. Gut Balance, a synbiotic supplement, increases fecal Lactobacillus paracasei but has little effect on immunity in healthy physically active individuals. Gut microbes. 2012;3(3):221-7. doi:10.4161/gmic.19579.

17. Sell J, Dolan B. Common Gastrointestinal Infections. Prim Care. 2018;45(3):519-32. doi:10.1016/j.pop.2018.05.008.

18. Kekkonen RA, Vasankari TJ, Vuorimaa T, Haahtela T, Julkunen I, Korpela R. The effect of probiotics on respiratory infections and gastrointestinal symptoms during training in marathon runners. International journal of sport nutrition and exercise metabolism. 2007;17(4):352-63. doi:10.1123/ijsnem.17.4.352.

19. Salarkia N, Ghadamli L, Zaeri F, Sabaghian Rad L. Effects of probiotic yogurt on performance, respiratory and digestive systems of young adult female endurance swimmers: a randomized controlled trial. Med J Islam Repub Iran. 2013;27(3):141-6.

20. Haywood BA, Black KE, Baker D, McGarvey J, Healey P, Brown RC. Probiotic supplementation reduces the duration and incidence of infections but not severity in elite rugby union players. Journal of science and medicine in sport. 2014;17(4):356-60. doi:10.1016/j.jsams.2013.08.004.

21. Pumpa KL, McKune AJ, Harnett J. A novel role of probiotics in improving host defence of elite rugby union athlete: A double blind randomised controlled trial. Journal of science and medicine in sport. 2019;22(8):876-81. doi:10.1016/j.jsams.2019.03.013.

22. Roberts JD, Suckling CA, Peedle GY, Murphy JA, Dawkins TG, Roberts MG. An Exploratory Investigation of Endotoxin Levels in Novice Long Distance Triathletes, and the Effects of a Multi- 
Strain Probiotic/Prebiotic, Antioxidant Intervention. Nutrients. 2016;8(11):733.

doi:10.3390/nu8110733.

23. Pugh JN, Sparks AS, Doran DA, Fleming SC, Langan-Evans C, Kirk B et al. Four weeks of probiotic supplementation reduces GI symptoms during a marathon race. European journal of applied physiology. 2019;119(7):1491-501. doi:10.1007/s00421-019-04136-3.

24. Jeukendrup AE. Nutrition for endurance sports: marathon, triathlon, and road cycling. J Sports Sci. 2011;29 Suppl 1:S91-9. doi:10.1080/02640414.2011.610348.

25. Armstrong LE, Lee EC, Armstrong EM. Interactions of Gut Microbiota, Endotoxemia, Immune Function, and Diet in Exertional Heatstroke. J Sports Med (Hindawi Publ Corp). 2018;2018:5724575-. doi:10.1155/2018/5724575.

26. Marchbank T, Davison G, Oakes JR, Ghatei MA, Patterson M, Moyer MP et al. The nutriceutical bovine colostrum truncates the increase in gut permeability caused by heavy exercise in athletes. Am J Physiol Gastrointest Liver Physiol. 2011;300(3):G477-G84. doi:10.1152/ajpgi.00281.2010.

27. Lambert GP, Lang J, Bull A, Pfeifer PC, Eckerson J, Moore G et al. Fluid restriction during running increases GI permeability. International journal of sports medicine. 2008;29(3):194-8. doi:10.1055/s-2007-965163.

28. Camus G, Poortmans J, Nys M, Deby-Dupont G, Duchateau J, Deby C et al. Mild endotoxaemia and the inflammatory response induced by a marathon race. Clin Sci (Lond). $1997 ; 92(4): 415-22$.

29. Lim CL, Pyne D, Horn P, Kalz A, Saunders P, Peake J et al. The effects of increased endurance training load on biomarkers of heat intolerance during intense exercise in the heat. Applied physiology, nutrition, and metabolism = Physiologie appliquee, nutrition et metabolisme . 2009;34(4):616-24. doi:10.1139/H09-021.

30. Jeukendrup AE, Vet-Joop K, Sturk A, Stegen J, Senden J, Saris WHM et al. Relationship between gastro-intestinal complaints and endotoxaemia, cytokine release and the acute-phase 
reaction during and after a long-distance triathlon in highly trained men. Clinical Science. 2000;98(1):47-55. doi:10.1042/cs19990258.

31. Selkirk GA, McLellan TM, Wright HE, Rhind SG. Mild endotoxemia, NF-kappaB translocation, and cytokine increase during exertional heat stress in trained and untrained individuals. American journal of physiology Regulatory, integrative and comparative physiology. 2008;295(2):R611-R23. doi:10.1152/ajpregu.00917.2007.

32. Brock-Utne JG, Gaffin SL, Wells MT, Gathiram P, Sohar E, James MF et al. Endotoxaemia in exhausted runners after a long-distance race. S Afr Med J. 1988;73(9):533-6.

33. Guy JH, Vincent GE. Nutrition and Supplementation Considerations to Limit Endotoxemia When Exercising in the Heat. Sports (Basel). 2018;6(1):12. doi:10.3390/sports6010012.

34. Lamprecht M, Bogner S, Schippinger G, Steinbauer K, Fankhauser F, Hallstroem S et al. Probiotic supplementation affects markers of intestinal barrier, oxidation, and inflammation in trained men; a randomized, double-blinded, placebo-controlled trial. J Int Soc Sports Nutr. 2012;9(1):45. doi:10.1186/1550-2783-9-45.

35. Masood MI, Qadir MI, Shirazi JH, Khan IU. Beneficial effects of lactic acid bacteria on human beings. Crit Rev Microbiol. 2011;37(1):91-8. doi:10.3109/1040841X.2010.536522. 36. Ku S, Park MS, Ji GE, You HJ. Review on Bifidobacterium bifidum BGN4: Functionality and Nutraceutical Applications as a Probiotic Microorganism. International journal of molecular sciences. 2016;17(9):1544. doi:10.3390/ijms17091544.

37. Gilliland SE, Speck ML. Antagonistic Action of Lactobacillus acidophilus Toward Intestinal and Foodborne Pathogens in Associative Cultures (1). J Food Prot. 1977;40(12):820-3. doi:10.4315/0362-028X-40.12.820.

38. Sanders ME, Klaenhammer TR. Invited review: the scientific basis of Lactobacillus acidophilus NCFM functionality as a probiotic. J Dairy Sci. 2001;84(2):319-31. doi:10.3168/jds.S0022-0302(01)74481-5. 
39. Azad MAK, Sarker M, Li T, Yin J. Probiotic Species in the Modulation of Gut Microbiota: An Overview. BioMed research international. 2018;2018:9478630-. doi:10.1155/2018/9478630. 40. Allen SJ, Jordan S, Storey M, Thornton CA, Gravenor MB, Garaiova I et al. Probiotics in the prevention of eczema: a randomised controlled trial. Archives of disease in childhood. 2014;99(11):1014-9. doi:10.1136/archdischild-2013-305799.

41. Garaiova I, Muchová J, Nagyová Z, Wang D, Li JV, Országhová Z et al. Probiotics and vitamin $\mathrm{C}$ for the prevention of respiratory tract infections in children attending preschool: a randomised controlled pilot study. European journal of clinical nutrition. 2015;69(3):373-9. doi:10.1038/ejcn.2014.174.

42. Allen SJ, Jordan S, Storey M, Thornton CA, Gravenor M, Garaiova I et al. Dietary supplementation with lactobacilli and bifidobacteria is well tolerated and not associated with adverse events during late pregnancy and early infancy. The Journal of nutrition. 2010;140(3):483-8. doi:10.3945/jn.109.117093.

43. Gleeson M, Bishop NC, Oliveira M, Tauler P. Daily probiotic's (Lactobacillus casei Shirota) reduction of infection incidence in athletes. International journal of sport nutrition and exercise metabolism. 2011;21(1):55-64. doi:10.1123/ijsnem.21.1.55.

44. Shing CM, Peake JM, Lim CL, Briskey D, Walsh NP, Fortes MB et al. Effects of probiotics supplementation on gastrointestinal permeability, inflammation and exercise performance in the heat. European journal of applied physiology. 2014;114(1):93-103. doi:10.1007/s00421-0132748-y.

45. Gill SK, Allerton DM, Ansley-Robson P, Hemmings K, Cox M, Costa RJ. Does Short-Term High Dose Probiotic Supplementation Containing Lactobacillus casei Attenuate Exertional-Heat Stress Induced Endotoxaemia and Cytokinaemia? International journal of sport nutrition and exercise metabolism. 2016;26(3):268-75. doi:10.1123/ijsnem.2015-0186.

46. Carbuhn AF, Reynolds SM, Campbell CW, Bradford LA, Deckert JA, Kreutzer A et al. Effects of Probiotic (Bifidobacterium longum 35624) Supplementation on Exercise Performance, 
Immune Modulation, and Cognitive Outlook in Division I Female Swimmers. Sports (Basel). 2018;6(4):116. doi:10.3390/sports6040116. 
Table 1. Impacts of probiotic supplementation on gut health in athletes.

\begin{tabular}{|c|c|c|c|c|c|}
\hline \multicolumn{6}{|c|}{ Impact of Probiotics on Gastrointestinal Symptoms During Training } \\
\hline Athletes & $\begin{array}{l}\text { Duration } \\
\text { of Suppl }\end{array}$ & $\begin{array}{l}\text { Single or } \\
\text { Multi-strain }\end{array}$ & $\begin{array}{l}\text { Bacterial Strains (Dosage); } \\
\text { Form }\end{array}$ & Outcome & \\
\hline $\begin{array}{l}\text { Marathon runners } \\
(\mathrm{M} \& W), n=119[18]\end{array}$ & $\begin{array}{l}12 \\
\text { weeks }\end{array}$ & Single strain & $\begin{array}{l}\text { Lactobacillus rhamnosus GG (4 x } \\
\left.10^{10} \mathrm{cfu} / \mathrm{d}\right) ; \text { Milk-based fruit drink }\end{array}$ & $\begin{array}{l}\text { Frequency of symptoms } \\
\text { Severity of symptoms }\end{array}$ & $\begin{array}{l}\leftrightarrow \\
\leftrightarrow\end{array}$ \\
\hline $\begin{array}{l}\text { Cyclists, triathletes, } \\
n=88[15]\end{array}$ & $\begin{array}{l}11 \\
\text { weeks }\end{array}$ & Single strain & $\begin{array}{l}\text { Lactobacillus fermentum (PCC®) } \\
\left(1 \times 10^{9} \mathrm{cfu} / \mathrm{d}\right) \text {; capsule }\end{array}$ & $\begin{array}{l}\text { Frequency of symptoms } \\
\text { Severity of symptoms }\end{array}$ & $\begin{array}{l}\uparrow \\
\downarrow\end{array}$ \\
\hline $\begin{array}{l}\text { Recreational to } \\
\text { competitive } \\
\text { endurance athletes } \\
(\mathrm{M} \& W), n=84[43]\end{array}$ & $\begin{array}{l}16 \\
\text { weeks }\end{array}$ & Single strain & $\begin{array}{l}\text { Lactobacillus casei Shirota ( } 6.5 \mathrm{x} \\
\left.10^{9} \mathrm{cfu} / \mathrm{d}\right) ; \text { drink }\end{array}$ & Frequency of symptoms & $\downarrow$ \\
\hline $\begin{array}{l}\text { Endurance swimmers } \\
(\mathrm{W}), \mathrm{n}=46[19]\end{array}$ & 8 weeks & Multi-strain & $\begin{array}{l}\text { Lactobacillus acidophilus, } \\
\text { Lactobacillus delbrueckii } \\
\text { bulgaricus, Bifidobacterium } \\
\text { bifidum, and Streptococcus } \\
\text { salivarus thermnophilus ( } 1.6 \times 10^{13} \\
\text { cfu/d); enriched yogurt }\end{array}$ & $\begin{array}{l}\text { Frequency of symptoms } \\
\text { Severity of symptoms }\end{array}$ & $\begin{array}{l}\leftrightarrow \\
\leftrightarrow\end{array}$ \\
\hline
\end{tabular}




\begin{tabular}{|c|c|c|c|c|c|}
\hline $\begin{array}{l}\text { Rugby players (M), } \\
n=30[20]\end{array}$ & 4 weeks & Multi-strain & $\begin{array}{l}\text { Lactobacillus gasseri ( } 2.6 \times 10^{9} \\
\text { cfu/d), Bifidobacterium bifidum ( } 2 \times \\
\left.10^{8} \mathrm{cfu} / \mathrm{d}\right) \text {, Bifidobacterium longum } \\
\left(2 \times 10^{8} \mathrm{cfu} / \mathrm{d}\right) \text {; gelatin capsule }\end{array}$ & Frequency of symptoms & $\leftrightarrow$ \\
\hline $\begin{array}{l}\text { Triathletes }(M \& W), \\
n=30[22]\end{array}$ & $\begin{array}{l}12 \\
\text { weeks }\end{array}$ & Multi-strain & $\begin{array}{l}\text { Lactobacillus acidophilus CUL-60 } \\
\left(1 \times 10^{10} \mathrm{cfu} / \mathrm{d}\right) \text {, Lactobacillus } \\
\text { acidophillus CUL-21 }\left(1 \times 10^{10}\right. \\
\text { cfu/d), Bifidobacterium bifidum } \\
\left.\text { CUL-20 ( } 9.5 \times 10^{9} \mathrm{cfu} / \mathrm{d}\right) \\
\text { Bifidobacterium animalis ssp lactis } \\
\left(5 \times 10^{8} \mathrm{cfu} / \mathrm{d}\right) \text {; capsule }\end{array}$ & $\begin{array}{l}\text { Frequency of symptoms } \\
\text { Severity of symptoms }\end{array}$ & $\begin{array}{l}\downarrow \\
\downarrow\end{array}$ \\
\hline $\begin{array}{l}\text { Runners (M\&W), n=20 } \\
\text { [23] }\end{array}$ & 4 weeks & Multi-strain & $\begin{array}{l}\text { Lactobacillus } \\
\text { acidophilus CUL60, L. acidophilus } \\
\text { CUL21, Bifidobacterium } \\
\text { bifidum CUL20, and } \\
\text { Bifidobacterium animalis ssp. } \\
\text { Lactis CUL34 (2.5 x } 1010 \mathrm{cfu} / \mathrm{d}) \text {; } \\
\text { capsule }\end{array}$ & Frequency of symptoms & $\downarrow$ \\
\hline
\end{tabular}




\begin{tabular}{|c|c|c|c|c|c|}
\hline $\begin{array}{l}\text { Rugby players }(M), \\
n=19[21]\end{array}$ & $\begin{array}{l}27 \\
\text { weeks }\end{array}$ & Multi-strain & $\begin{array}{l}\text { Lactobacillus rhamnosus, } \\
\text { Lactobacillus casei, Lactobacillus } \\
\text { acidophilus, Lactobacillus } \\
\text { plantarum, Lactobacillus } \\
\text { fermentum, Bifiodbacterium lactis, } \\
\text { Bifidobacterium bifidum, } \\
\text { Streptococcus thermophilus ( } 6 \mathrm{x} \\
10^{10} \mathrm{cfu} / \mathrm{d} \text { ); capsule }\end{array}$ & Frequency of symptoms & $\leftrightarrow$ \\
\hline \multicolumn{6}{|c|}{ Impact of Probiotics on Gastrointestinal Symptoms During a Single Event } \\
\hline Event & $\begin{array}{l}\text { Duration } \\
\text { of Suppl }\end{array}$ & $\begin{array}{l}\text { Single or } \\
\text { Multi-strain }\end{array}$ & $\begin{array}{l}\text { Bacterial Strains, Dosage, and } \\
\text { Form }\end{array}$ & Outcome & \\
\hline $\begin{array}{l}\text { Marathon }(M \& W) \text {, } \\
n=20[23]\end{array}$ & 4 weeks & Multi-strain & $\begin{array}{l}\text { Lactobacillus } \\
\text { acidophilus CUL60, L. acidophilus } \\
\text { CUL21, Bifidobacterium } \\
\text { bifidum CUL20, and } \\
\text { Bifidobacterium animalis subsp. } \\
\text { Lactis CUL34 (2.5 x } 1010 \mathrm{cfu} / \mathrm{d}) \text {; } \\
\text { capsule }\end{array}$ & $\begin{array}{l}\text { Severity of symptoms (during final } \\
1 / 3 \text { of marathon race) }\end{array}$ & $\downarrow$ \\
\hline
\end{tabular}




\begin{tabular}{|c|c|c|c|c|c|}
\hline $\begin{array}{l}\text { Run to fatigue in the } \\
\text { heat [44] }\end{array}$ & 4 weeks & Multi-strain & $\begin{array}{l}\text { Lactobacillus acidophilus ( } 7.4 \times \\
\left.10^{9} \mathrm{cfu} / \mathrm{d}\right), \text { L. rhamnosus }(1.6 \mathrm{x} \\
\left.10^{10} \mathrm{cfu} / \mathrm{d}\right), \text { L. casei }\left(9.5 \times 10^{9}\right. \\
\mathrm{cfu} / \mathrm{d}), \text { L. plantarum }\left(3.2 \times 10^{9}\right. \\
\mathrm{cfu} / \mathrm{d}), \text { L. fermentum }\left(1.4 \times 10^{9}\right. \\
\mathrm{cfu} / \mathrm{d}), \text { Bifidobacterium lactis }(4.1 \times \\
\left.10^{9} \mathrm{cuf} / \mathrm{d}\right), \text { B. breve }\left(1.4 \times 10^{9}\right. \\
\mathrm{cfu} / \mathrm{d}), \text { B. bifidum }\left(5 \times 10^{8} \mathrm{cfu} / \mathrm{d}\right) \\
\text { and Streptococcus thermophilus } \\
\left.2.3 \times 10^{9} \mathrm{cfu} / \mathrm{d}\right) ; \text { capsule }\end{array}$ & Severity of symptoms & $\leftrightarrow$ \\
\hline \multicolumn{6}{|c|}{ Impact of Probiotics on Gut Barrier Function During Training } \\
\hline Athletes & $\begin{array}{l}\text { Duration } \\
\text { of Suppl }\end{array}$ & $\begin{array}{l}\text { Single or } \\
\text { Multi-strain }\end{array}$ & $\begin{array}{l}\text { Bacterial Strains, Dosage, and } \\
\text { Form }\end{array}$ & Outcome & \\
\hline $\begin{array}{l}\text { Endurance athletes } \\
(\mathrm{M}), \mathrm{n}=23[34]\end{array}$ & $\begin{array}{l}14 \\
\text { weeks }\end{array}$ & Multi-strain & $\begin{array}{l}\text { Bifidobacterium bifidum W23, } \\
\text { Bifidobacterium lactis W51, } \\
\text { Enterococcus faecium W54, } \\
\text { Lactobacillus acidophilus W22, } \\
\text { Lactobacillus brevis W63, and }\end{array}$ & $\begin{array}{l}\text { Zonulin (increases as barrier } \\
\text { function decreases) }\end{array}$ & $\downarrow$ \\
\hline
\end{tabular}




\begin{tabular}{|c|c|c|c|c|c|}
\hline & & & 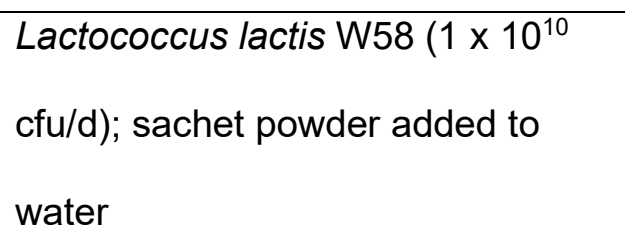 & & \\
\hline $\begin{array}{l}\text { Physically active (M), } \\
n=22[16]\end{array}$ & 3 weeks & Multi-strain & $\begin{array}{l}\text { Lactobacillus paracasei subs } \\
\text { Paracasei }\left(4.6 \times 10^{8} \mathrm{cfu} / \mathrm{d}\right) \text {, } \\
\text { Bifidobacterium animalis ssp lactis } \\
\left(6 \times 10^{8} \mathrm{cfu} / \mathrm{d}\right) \text {, Lactobacillus } \\
\left.\text { acidophilus LA-5 ( } 4.6 \times 10^{8} \mathrm{cfu} / \mathrm{d}\right) \\
4.6 \times 10^{8} \text { Lactobacillus } \\
\left.\text { rhamnosus GG ( } 4.6 \times 10^{8} \mathrm{cfu} / \mathrm{d}\right) \text {; } \\
\text { capsules }\end{array}$ & $\begin{array}{l}\text { Lactulose:mannitol (increases as } \\
\text { barrier function decreases) }\end{array}$ & $\leftrightarrow$ \\
\hline $\begin{array}{l}\text { Runners in training } \\
(n=8)[45]\end{array}$ & 1 week & Single strain & $\begin{array}{l}\text { Lactobacillus casei }\left(1 \times 10^{11} \mathrm{cfu} / \mathrm{d}\right) \text {; } \\
\text { drink }\end{array}$ & Serum endotoxemia & $\uparrow$ \\
\hline $\begin{array}{l}\text { Swimmers }(W), n=17 \\
{[46]}\end{array}$ & 6 weeks & Single strain & $\begin{array}{l}\text { Bifidobacterium longum } 35624 \text { (1 x } \\
\left.10^{9} \mathrm{cfu} / \mathrm{d}\right) ; \text { capsule }\end{array}$ & Serum endotoxemia & $\leftrightarrow$ \\
\hline \multicolumn{6}{|c|}{ Impact of Probiotics on Gut Barrier Function During Competition or Event } \\
\hline $\begin{array}{l}\text { Competition or } \\
\text { Event }\end{array}$ & $\begin{array}{l}\text { Duration } \\
\text { of Suppl }\end{array}$ & $\begin{array}{l}\text { Single or } \\
\text { Multi-strain }\end{array}$ & $\begin{array}{l}\text { Bacterial Strains, Dosage, and } \\
\text { Form }\end{array}$ & Outcome & \\
\hline
\end{tabular}




\begin{tabular}{|c|c|c|c|c|c|}
\hline $\begin{array}{l}\text { Run to fatigue in the } \\
\text { heat [44] }\end{array}$ & 4 weeks & Multi-strain & $\begin{array}{l}\text { Lactobacillus acidophilus }(7.4 \times \\
\left.10^{9} \mathrm{cfu} / \mathrm{d}\right), \text { L. rhamnosus }(1.6 \mathrm{x} \\
\left.10^{10} \mathrm{cfu} / \mathrm{d}\right), \text { L. casei }\left(9.5 \times 10^{9}\right. \\
\mathrm{cfu} / \mathrm{d}), \text { L. plantarum }\left(3.2 \times 10^{9}\right. \\
\mathrm{cfu} / \mathrm{d}), \text { L. fermentum }\left(1.4 \times 10^{9}\right. \\
\mathrm{cfu} / \mathrm{d}), \text { Bifidobacterium lactis }(4.1 \times \\
\left.10^{9} \mathrm{cuf} / \mathrm{d}\right), \text { B. breve }\left(1.4 \times 10^{9}\right. \\
\mathrm{cfu} / \mathrm{d}), \text { B. bifidum }\left(5 \times 10^{8} \mathrm{cfu} / \mathrm{d}\right) \\
\text { and Streptococcus thermophilus } \\
\left.2.3 \times 10^{9} \mathrm{cfu} / \mathrm{d}\right) ; \text { capsule }\end{array}$ & $\begin{array}{l}\text { Serum endotoxemia } \\
\text { Serum claudin (increases as } \\
\text { barrier function decreases) }\end{array}$ & $\begin{array}{l}\leftrightarrow \\
\leftrightarrow\end{array}$ \\
\hline $\begin{array}{l}\text { Marathon }(M \& W) \text {, } \\
n=30[22]\end{array}$ & $\begin{array}{l}12 \\
\text { weeks }\end{array}$ & Multi-strain & $\begin{array}{l}\text { Lactobacillus acidophilus CUL-60 } \\
\left(1 \times 10^{10} \mathrm{cfu} / \mathrm{d}\right) \text {, Lactobacillus } \\
\text { acidophillus CUL-21 ( } 1 \times 10^{10} \\
\text { cfu/d), Bifidobacterium bifidum } \\
\left.\text { CUL-20 ( } 9.5 \times 10^{9} \mathrm{cfu} / \mathrm{d}\right) \\
\text { Bifidobacterium animalis } \\
\text { subspecies lactis CUL-34 (5 } \times 10^{8} \\
\text { cfu/d); capsule }\end{array}$ & $\begin{array}{l}\text { Serum endotoxemia } \\
\text { Lactulose:mannitol (pro } \leftrightarrow \text {, } \\
\text { placebo } \uparrow \text { ) }\end{array}$ & $\begin{array}{c}\leftrightarrow \\
\downarrow\end{array}$ \\
\hline
\end{tabular}




\begin{tabular}{|l|l|l|l|l|}
\hline Marathon (M\&W), & 4 weeks & Multi-strain & $\begin{array}{l}\text { Lactobacillus acidophilus CUL60, } \\
\text { L. acidophilus CUL21, }\end{array}$ & Lactulose:mannitol \\
& & $\begin{array}{l}\text { Bifidobacterium bifidum CUL20, } \\
\text { and Bifidobacterium animalis } \\
\text { subsp. Lactis CUL34 }\left(2.5 \times 10^{10}\right.\end{array}$ & \\
& & & \\
& & &
\end{tabular}

$\mathrm{M}=$ =men; $\mathrm{W}=$ =women; Suppl=supplementation; $c f u / d$ = colony forming units per day; ssp.= subspecies 